\title{
From prescribed to real rotations: a means of collective protection for the health of workers in a soft drink factory.
}

\author{
R. Simões ${ }^{\mathrm{a},{ }^{*}}$, F. Daniellou ${ }^{\mathrm{a}}$ and A. Nascimento ${ }^{\mathrm{b}}$ \\ ${ }^{a}$ École Doctorale de Sciences Sociales, Laboratoire d'Ergonomie, Université Bordeaux 2, 146 rue Léo Saignat, \\ Bordeaux, France. \\ ${ }^{\mathrm{b}}$ Conservatoire National des Arts et Métiers (Cnam), Laboratoire d'Ergonomie, 41 rue Gay Lussac, Paris, \\ France.
}

\begin{abstract}
This article describes a particular way developed by employees to respond to the constraints of a very restrictive manufacturing plant: the mutual cooperation. Facing a very strict organizational context, the production workers can only rely on themselves to cope with the constraints of work. In this context, a complex system of strategies is deployed, resulting in a work environment governed by the sense of collaboration and mutual cooperation. The objectives of the implemented strategies, however, go beyond the attempts to reduce the work overload. They may be linked to a way of maintaining high levels of productivity and a way for workers to keep their jobs. We hope to contribute, through this study, to the general knowledge of the strategies developed by workers in production lines in order to minimize the pains.
\end{abstract}

Keywords: collective strategies, collective work, physical workload, margin of maneuver, cooperation.

\section{Introduction}

We live in an era where companies are going through rapid changes which require the development of new skills and strategies by the workers, as well as the rearrangement of their activities. In this way, topics such as "collective activities", "job rotation" and "the correlation between margin of maneuver and musculoskeletal injuries" are increasingly placed in the context of team work in big companies and the scientific community which studies the issue.

Vézina [13] shows that researches on 'collective activities' as a response to the constraints of the system can guide the scientific study and ergonomic principles to new perspectives.

This research sought to understand the collective strategies used by production workers at the production line of a big soft drink factory in Brazil. We selected a subgroup of operators who perform the toughest tasks, especially those in charge of loading and unloading boxes of bottles whose rates of absenteeism were higher. The operators of this subgroup do job rotations changing their positions: it was set up by the company as a way to reduce the pains and the absenteeism.

Despite this strategy of the company, rates of absenteeism and complaints about aches and pains were still too high. Among all the employees, four teams of six operators $(\mathrm{n}=24)$ were studied so as to understand the mechanism of the job rotation, to identify any work overload they have suffered from and the strategies used by them.

This article aims to describe a particular way that employees developed to respond to the constraints of a very restrictive manufacturing plant: self-help and mutual cooperation. Through a qualitative method based on techniques of showdown, we can observe that the production operators can only rely on them-

${ }^{*}$ Corresponding author: raoni.france@gmail.com 
selves to cope with the constraints of work at the production line of a beverage company: they organize themselves in order to ensure productivity and protect their health. In this context, a complex system of strategies is deployed, resulting in a work environment governed by a sense of mutual cooperation and collective protection so as to minimize fatigue and difficulty during the workday.

\subsection{The collective work and the margins of maneuver}

Several researches [1- 4, 7] highlight the main role of collective activities in the technical systems, in terms of performance, health, security and reliability.

To look after their health, the workers develop strategies which aim to avoid pains and/or fatigue [3]. These strategies consist in diminishing motions, reducing the efforts or protecting the parts of the body which are sore. In a collective way, the workers reorganize the distribution of work tasks so as to protect the ones who have already been struck by occupational diseases [1].

In order to apply these regulations, the notion of the margins of maneuver is essential. Some authors $[5,6,13]$ agree with each other as they say that the arrangement of the workplace is the first element that increases the margins of maneuver. Under the same circumstances, expanding the workplace for each employee of the company allows them to anticipate or retard their actions in case of need.

For the workers to have the possibilities of regulations which aim to ensure the work efficiency, they need to have the possibility to increase their margins of maneuver of space and time as well. Coutarel [4] supports this affirmation stating that the possibilities of regulations at work increases when margins of maneuver of the workers also increase.

\subsection{Job rotation}

The job rotation in companies is often implemented as one of the attempts made by the managers in order to find a solution to the work overload issue. Coutarel et al. [5] state that job rotations are often presented as " the miraculous solution» to the RSI (repetitive strain injuries).

According to Vézina [14] a person does job rotations when "they change positions following a cyclical and rhythmical established order". Every position change needs to go through a brief learning period regardless of the competences of the worker.
This period varies according to the operations which will be conducted and according to the individuals. A fast job rotation in which one did not take into account this brief learning process will certainly have bad consequences: the workers will have some difficulties and the work may not be productive [14].

Having some time to learn a new task means to have margins of maneuver to perform it. Thus, the implementation of job rotations for a group of workers cannot dissociate from the issue of increasing the margins of maneuver of the workers in that group [5].

\subsection{The self-regulation of the group}

In order to be able to discuss about the process of regulation implemented by the operators, we need to define the notions of strains and constraints which are central to the understanding of the workload. According to Falzon [10], the constraint is determined by the task and it corresponds to a certain level of requirements. The strain results out of the work constraints and the resources of the employees. If the strain is considered as severe or heavy by the employees, then they will try to change their performance or strategies in order to alleviate it. When a worker does not have enough margins of maneuver to change their performance in order to keep up a good functioning of the system, the possibilities of adaptation of the body to the job requirements can be difficult and then the work ends up overloaded, slowing down or preventing the internal regulation processes. And from that, the injuries may occur [14]

The objective of a group that works in a collective way is to regulate the internal workload [1]. Leplat [11] considers the work group as a « self-active system » in which the activity depends on the characteristics of the group, the characteristics of the task which has to be accomplished as well as the association between both characteristics. The author states that the members of the group can protect themselves by reorganizing the tasks so as to reestablish a good balance of their individual workload when work overloads are detected by any coworker among them.

Nevertheless, for it to be possible, it is necessary that the workers have a certain degree of margins of maneuver and autonomy so that they will be able to get rid of some rules.

A team that self-regulates can redefine its own goals as well as the ways to achieve them through the distribution of tasks and through the way they perform these tasks. The team self-regulation is, then, a 
flexibility factor which allows the group to adapt to the upheavals and contingencies.

\section{The Methods}

\subsection{The context and the samples}

The company at issue produces soft drinks in bottles (both glass and plastic bottles) and cans. The production line that was selected to this study, is called Line 1, and had the highest number of complaints in the company mainly related to the repetitiveness and to the pains in the back and shoulders felt by the employees. These factors are associated, as they put it, with the characteristics of the physical work itself and the monotony at work.

The Line 1 comprises 84 employees who work 12 hours then have 36 hours off. There are, thus, four groups (two in both day and night shifts), 21 workers in each of them.

For this study we selected a group of workers who perform the tasks considered as the heaviest ones, evidently the manual loading and unloading of bottle boxes, and where the rate of absenteeism is high. The workers in this group do job rotation in their positions at work; this was the strategy of the company to reduce the work penalties and absenteeism. Despite this strategy, the rates of absenteeism and the complaints about pains are still too high. Four groups of six workers (total 24) were studied with a focus on the analysis of the mechanism of the job rotation by identifying any work overload the employees bear and the strategies they use to face it.

\subsection{The methodology}

The methods used by them were essentially qualitative, combining the observations in situ, the methods of confrontation and the use of a questionnaire of health. The methodological choice of this work was made in favor of a methodology which encourages workers to talk and think about their activities. This approach was important because, on one hand, they did not have any room for that. On the other we realized that they had different point of views about their representations at work considered as "simple" and "easy" or "demanding" and "difficult". Thus, several techniques of analysis were developed and had the following goals:

$\Rightarrow$ describe the mechanisms of prescribed and real rotations;
$\Rightarrow$ identify the types and reasons of the collective strategies which were implemented;

$\Rightarrow$ identify the consequences of the work on the health of the employee and the means used to diminish the constraints;

$\Rightarrow$ discuss the constraints and conditions of the work.

We started by handing out some health questionnaires in order to understand not only the pains and discomfort felt by the workers, but also the impact that they can have on their work. The questionnaire was handed out to all the employees in the four groups that were present and was applied in two different dates: in December 2009 and June 2010. Thus, 24 people answered the questionnaire in the first time and 24 other people had their turn in the second one, which totals 48 questionnaires. It is necessary to take into account that 7 workers among the ones who answered the questionnaire in the first turn resigned between Dec/2009 and June/2010, i.e. 33\% of the group.

Along with the handing out of the questionnaires, observations on the activities were also made. In total, we count 9 days of open observations (about 4 fours per day) and 11 days of systemic observations (about four hours per day) with the workers in all of the 4 groups. The realization of the observations aimed to identify the types of job rotation and the strategies adopted by the workers as well as to identify the particularities and differences between job rotations with or without absence of one or several workers.

Some individual interviews were also done in order to complete the information obtained during the phase of observation. This way, 12 interviews were done with the workers in each group. Due to time constraints, each interview took 20 minutes.

Some techniques of interview using alloconfrontation [12] were applied with 6 workers. The goal was to invite them to reflect on their work, on the perception of job rotation and also to understand better the collective and operational strategies. These 6 workers in the day shift were confronted with the observations of the activities of their colleagues, and each interview lasted about 20 minutes. At another moment, two thirty-minute interviews of collective allo-confrontation also took place, one in March 2010 and other one in June 2010. During the interviews, the workers of the group discussed about the observations of the activity of another colleague in the group. 


\section{Results}

The quantitative analysis shows us that the assistants are young and physically strong. According to the HR department of the company, $69 \%$ of them were in their early twenties, between 20 and 24 years old (the oldest one is no older than 35 years old), and the average duration in their function is between 7 months and a year. The data collected in June 2010 confirm the registers of the HR department. They show that the majority of the group is between 20 and 24 years old and were working for a period of time that goes in between three to seven months in the function (Figure 1).

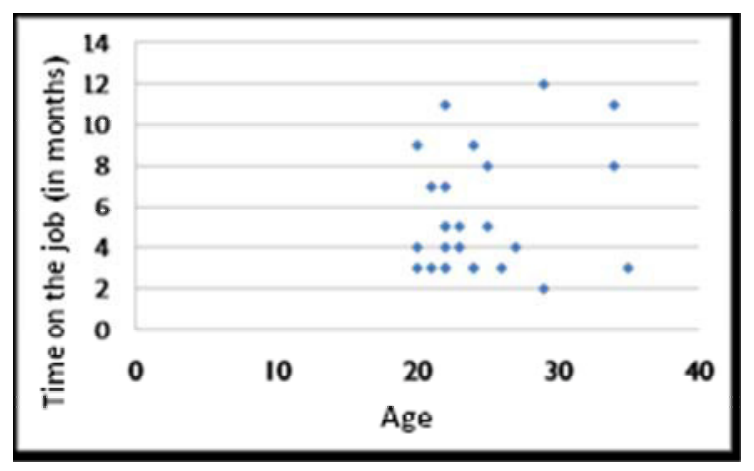

Fig. 1 : Graph showing the age and time on the job.

Such a weak permanence in the function is explained by the high turn-over at the line. In 2009, the line 1 had the highest rate of abandonments, in numbers 18 and in percentage $60 \%$ of the group had resigned. The reason of the abandonments, according to the HR department, is due to the "mass resignation" that's to say, it's the assistants who quit their jobs.

\subsection{The prescribed rotation}

The job rotation which is prescribed to the workers is: when the workforce is stable it is divided in twosomes every 30 minutes. As the group of operators is comprised of 6 people, 3 twosomes are set up (Figure 2).

The first twosome, identified by the number 1 in the figure 2, comprises two operators who are responsible for the manual unloading of bottle boxes.
The second twosome identified by the number 2 , comprises 2 operators who are responsible for the manual loading of bottle boxes. The third one, identified by the number 3 , comprises an assistant in charge of taking out the straws in the bottles and other one in charge of the stacking boxes on the pallets.

The prescribed rotation was conducted as the following way: every 30 minutes, the twosome 1 goes towards the twosome 2 . The twosome 2 splits, one of them goes to the site where they can take out the straws and the other one to the stacking site. The twosome 3 performs the manual loading. The pictures number 2 shows the prescribed rotation that was implemented by the company.

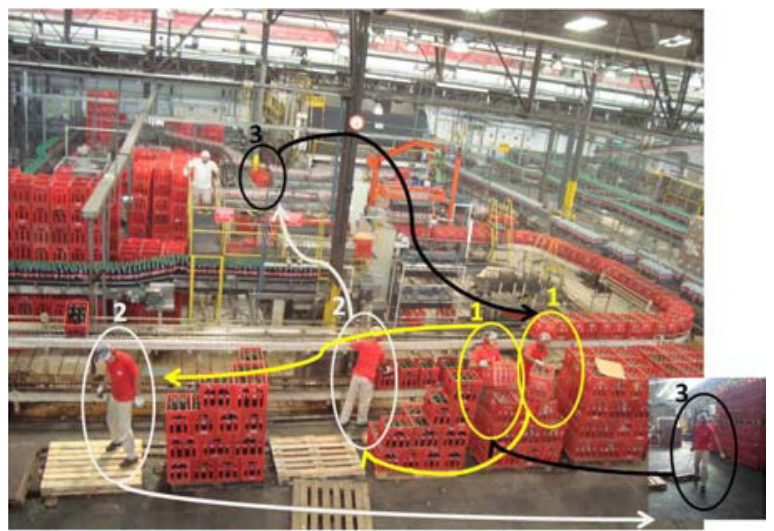

Fig. 2 : Job rotation prescribed by the company when the workforce is stable.

The results of the first observations called our attention to the types of rotation that were adopted by the operators, often different from the ones prescribed by the company. Along with that, we could notice the diversity of strategies used by the workers to protect themselves and try to manage collectively some of the constraints they have. We will describe below the main strategies used by the group according to their goal.

\subsection{The employed strategies}

\subsubsection{Minimizing the overall exposure to the workload.}

The operators adopt different operational modes trying to diminish their exposure to the workload at the production line. They change, for example, the type of rotation that was prescribed when some of the 
employees are absent. Performing other different types of rotation, the operators try to reduce the permanence time at the loading and unloading stations, considered as the heaviest ones. This happens when one or two employees of the group are absent.

In case of absence of an operator the pallet stacking station is shut and the job rotation is no longer performed in twosomes, but in «Indian queues". The time of rotation is reduced from 30 to 15 minutes. In this way, the operators also reduce the time of direct exposure to the weight lifting, from 2 to 1 hour. However, in case of absence of two operators the job rotation is performed in twosomes again and the time of rotation reverts to 30 minutes. The margins of maneuver are, then, reduced. Since there are only 4 operators (instead of 6), a position hierarchy is defined: only the loading and unloading of boxes are kept, of which loading is considered as the "heaviest" task. Figure 3 shows two systems of job rotation when one or two operators are absent.

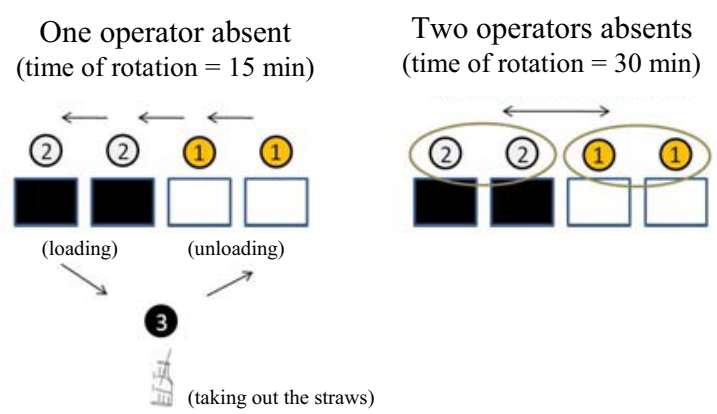

Fig. 3: Adopted strategies when an assistant is absent.

In some work overload situation, the operators can also be helped by other operators from other production lines, even if the total number of operators at Line 1 reaches its total. The seventh operator integrates the job rotation system. This is also a way to reduce the time and, then, the exposure to the loading. Once the station has one more operator, the total amount of boxes is divided by three operators instead of two as it usually functions (Figure 4).

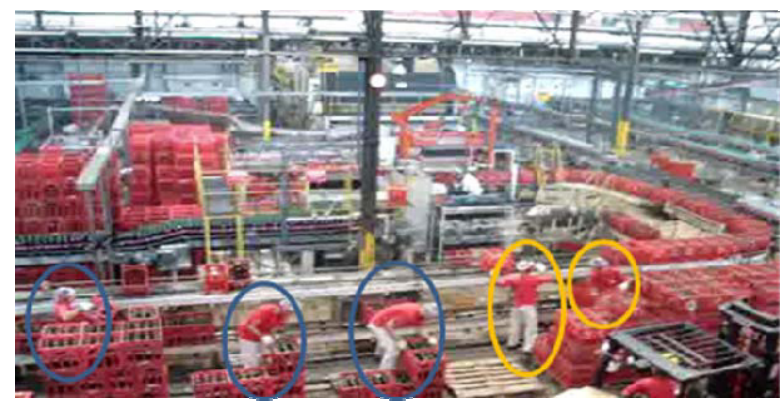

Fig. 4 : Presence of three operators at the loading station instead of two.

\subsubsection{Removing a task of job rotation to protect a member of the group}

The operators formulate several strategies to protect themselves. That's the case with the beginners, among the twosomes, or even when a member of the group does not feel physically well complaining about backache and sore arms. In this case, the operator at issue can be exempted from the job rotation during a certain time and replaced in "light" tasks, considered to be less arduous, for instance the taking out of straws in the bottles. In this case, the rotation changes even more, functioning in Indian queue and not including the removed task. Figure 5 illustrates this situation.

\section{3}

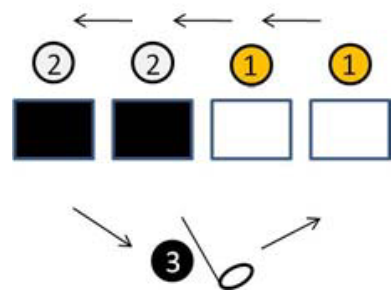

(stacking boxes on the pallets)

Fig. 5: Strategy to exempt someone from the job rota tion.

Another example takes place when the trolley brings a pallet with old boxes, considered as heavier and more difficult to manipulate. In this case, two operators in the unloading station carry together the same box instead of carrying it alone which is the usual procedure. That's the mutual aid to tackle with old boxes on the pallet which is more uncomfortable. (Figure 6). 

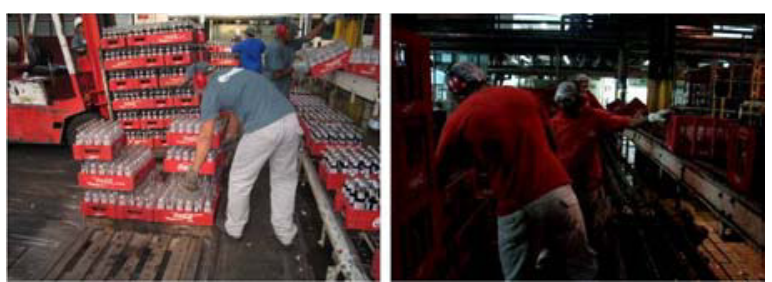

Fig. 6 : Unloading old boxes on the left and new boxes on the right.

\subsubsection{The distribution to take pauses}

The operators make use of strategies to take some pauses during the activities in order to rest a little. In general, the operators in the loading station carry the boxes which are brought to the line, each one carries two boxes at once and stack them on their own pallet. However an agreement can be negotiated by the twosome since they do not carry together the boxes and only one of them will be in charge of stacking boxes on the pallet while the other one rests. When the stacking of boxes on the pallet is almost done, the assistants invert their positions so that the one who stacks boxes rests while the other one who was taking a pause has his turn to stack. Figure 7 shows an assistant stacking boxes all alone (on the right), while his colleague (on the left) takes a pause and cleans his face with a cloth.

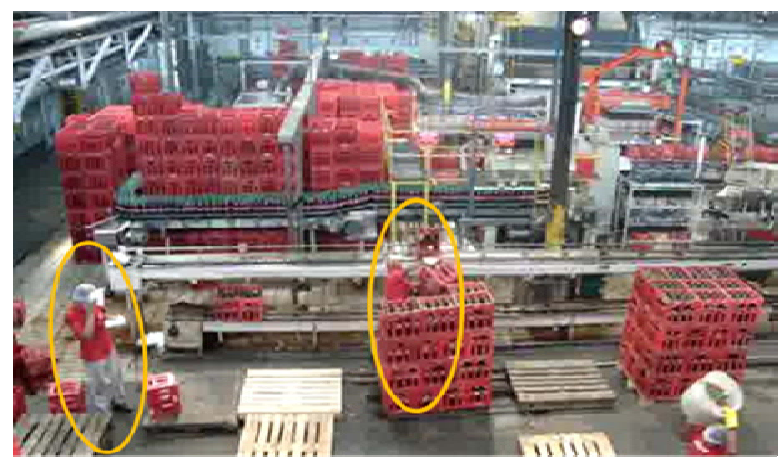

Fig. 7 : Example of a strategy to take pauses in the activity.

\section{Discussion}

The operators of the analyzed group change some rules which were established by the company, they adopt other rotation systems, aiming to take pauses, protecting and being protected by their colleagues, protecting and instructing the beginners, giving pre- ferential treatment to the colleagues in pause so that they will also take some pauses, devising means of aid and mutual collaboration. By grasping the margins of maneuver concepts, Vézina [13] states that the collective work is one of the methods to widen the margins of maneuver and, as a result, to preserve the health.

The company put into action the job rotation as a way to reduce the absenteeism. However, the absenteeism rate and the complaints are still high. Line 1 is the sector in which the majority of workers hand in their resignation. In spite of that, a complex system of strategies is put into action by production operators, maximizing the possibilities of work performance.

Nevertheless, the implementation of these strategies is not sufficient to avoid the high rates of absenteeism and complaints. The operators make use of them, though. The goals of these strategies go beyond the attempts to minimize the work overload. These goals can be linked to the deadening of pains which is seen as a way to keep up the productivity. Dejours et al. [8] show us that the implementation of the defensive strategies is necessary to the continuation of work.

Some other authors show similar results in their studies. Caroly [2] shows us that the re-elaboration of rules for the group of work aims not only to reduce the constraints, but also to manage the conflicts of objectives and to find the ways to do "a good job". The results of the study done by Falardeu \& Vézina [9] in a pork slaughterhouse considers that job rotation represents a solution found by the operators to be able to keep up in their posts and to keep up the operational activity.

The workers who were analyzed have few possibilities to regulate and few margins of maneuver. A surprising fact is that in a very restrictive environment the operators developed many strategies ruled by the mutual cooperation and collective protection aiming to minimize the fatigue and the pains.

This situation reminds the concepts of the "selfactive system" mentioned by Leplat [11]. Dejours et al. [8] affirm that "in a provocative attitude, the operators can take the role of active agents instead of victim so that they can manage the defense strategies $»$.

In order to face a strict organizational context, the production operators look for some help from the only available source: themselves. Very often, they can only rely on themselves to face the company constraints and avoid damages to their health [5].

As a whole, it seems that the strategies shown in this study aim not only to minimize the pains and the 
work overload, but also to manage them in the group, a solution that the employees found to keep up a good pace of productivity. From this context an envi- ronment inspired by the feeling of collaboration is established prioritizing the self-managed cooperation procedures.

\section{References}

[1] Assunção, A. A. (1998). De la déficience à la gestion collective du travail : les troubles musculosquelettiques dans la restauration collective. Thèse de doctorat en ergonomie, Paris 5 : Ecole Pratique de Hautes Etudes, Paris.

[2] Caroly, S. (2010). L'activité collective et la réélaboration des règles : des enjeux pour la santé au travail. Thèse de HDR en ergonomie. Université Victor Segalen Bordeaux 2, Bordeaux.

[3] Chassaing, K. (2006). Elaboration, structuration et réalisation des gestuelles de travail: les gestes dans l'assemblage automobile, et dans le coffrage des ponts d'autoroute. Thèse de Doctorat en ergonomie. CNAM, Paris.

[4] Coutarel, F. (2004). La prévention des troubles musculosquelettiques en conception: quelles marges de manoeuvre pour le déploiement de l'activité ? Thèse de doctorat en ergonomie. Université Victor Segalen.

[5] Coutarel F., Daniellou, F. \& Dugué, B. (2003). Interroger l'organisation du travail au regard des marges de manœuvre en conception et en fonctionnement. Pistes, v. 5, n. 2, http://pettnt/pistes/v5n2/articles/v5n2a2.htm.

[6] Daniellou, F. (2003). De la rotation sur les postes à la santé a travail. Synthèse du colloque «La rotation, est-ce une solution? ». Pistes, $\quad$ v. 5, n. http://pettnt/pistes/v5n2/articles/v5n2a12.htm.

[7] De La Garza, C., Weill-Fassina, A. (1995). Les modalités de gestion collective des risques ferroviaires sur des chantiers d'entretien des voies. Recherche, transports, sécurité, n. 49, p. 73-84.

[8] Dejours, C., Abdouchelli, E., Jayet, C. (1994). Psicodinâmica do trabalho: contribuições da escola dejouriana à análise da relação prazer, sofrimento e trabalho. São Paulo: Atlas.

[9] Falardeau, A., Vézina, N. (2004). Apport de différentes sources de données à la description comparée des contraintes et à l'amélioration d'un groupe de postes occupés en rotation. Pistes, v. 6, n. 1, http://pettnt/pistes/v6n1/articles/v6n1a7.htm.

[10] Falzon, P. (2004). Ergonomie Paris : PUF.

[11]Leplat, J. (2006). La notion de régulation dans l'analyse de l'activité. Pistes, v. 8, n. 1, 25 p.

[12] Mollo, V., Falzon, P. (2004). Auto- and allo-confrontation as tools for reflective activities. Applied Ergonomics, v. 35, n. 6, p. $531-540$.

[13] Vézina, N. (2003). La rotation, est-ce une solution? Pistes, v. 5, n. 2, http://pettnt/pistes/v5n2/articles/v5n2a10.htm.

[14] Vézina, N. (2005). La rotation des postes peut-elle représenter un moyen de prévention des troubles musculo-squelettiques? Actes du ler Congrès francophone sur les TMS du membre supérieur, n. 24, p. 12-16. Nancy : 30 et 31 Mai 2005. 